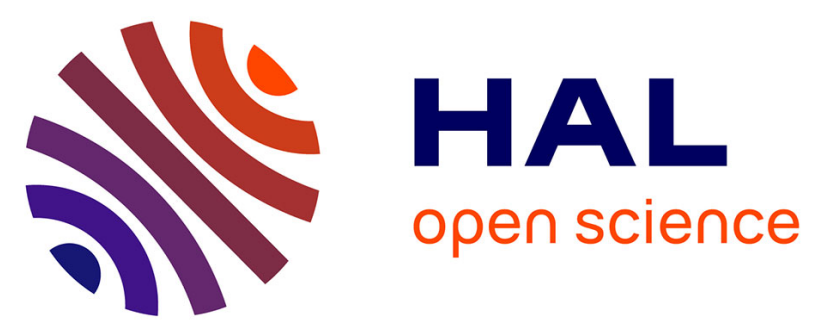

\title{
Effect of light absorption rate and nitrate concentration on TAG accumulation and productivity of Parachlorella kessleri cultures grown in chemostat mode
}

\author{
R. Kandilian, Ahmed Taleb, V. Heredia, G. Cogne, Jeremy Pruvost
}

\section{- To cite this version:}

R. Kandilian, Ahmed Taleb, V. Heredia, G. Cogne, Jeremy Pruvost. Effect of light absorption rate and nitrate concentration on TAG accumulation and productivity of Parachlorella kessleri cultures grown in chemostat mode. Algal Research - Biomass, Biofuels and Bioproducts, 2019, 39, pp.101442. 10.1016/j.algal.2019.101442 . hal-02533870

\section{HAL Id: hal-02533870 \\ https://hal.science/hal-02533870}

Submitted on 17 Apr 2020

HAL is a multi-disciplinary open access archive for the deposit and dissemination of scientific research documents, whether they are published or not. The documents may come from teaching and research institutions in France or abroad, or from public or private research centers.
L'archive ouverte pluridisciplinaire HAL, est destinée au dépôt et à la diffusion de documents scientifiques de niveau recherche, publiés ou non, émanant des établissements d'enseignement et de recherche français ou étrangers, des laboratoires publics ou privés. 


\title{
Effect of light absorption rate and nitrate concentration on TAG accumulation and productivity of Parachlorella kessleri cultures grown in chemostat mode
}

\author{
R. Kandilian, A. Taleb, V. Heredia, G. Cogne, J. Pruvost \\ Université de Nantes, CNRS, GEPEA, UMR-CNRS 6144, Bd de l'Université, CRTT-BP 406, 44602 Saint-Nazaire Cedex, France
}

\section{A R T I C L E I N F O}

\section{Keywords:}

Light transfer

Biofuels

TAG

Chemostat

Lipids

Microalgae

\begin{abstract}
A B S T R A C T
This study aims to elucidate the role of light absorption rate and nitrate concentration on triacylglycerol (TAG) productivity and cellular TAG accumulation in nitrogen limited Parachlorella kessleri cultures grown in chemostat mode. In batch operated nitrogen starved cultures the cells accumulate large amounts of TAGs at the expense of biomass growth leading to severe decrease in cell division rate prompting eventual cell death. In PBRs operated in continuous mode cell multiplication can persist in nitrogen limited conditions with simultaneous TAG accumulation. $P$. kessleri cultures were grown in a flat-plate PBR with constant dilution rate of $0.011 / \mathrm{h}$ and feed-medium nitrate concentration ranging from 1 to $16 \mathrm{mM}$. The steady-state biomass, pigment, carbohydrate, protein, total lipid, and TAG concentrations as well as the spectral absorption and scattering cross-sections of the microalgae were measured for each culture. These were used to estimate the specific mean rate of photon absorption (MRPA) in the PBR. Maximum areal TAG productivity of $2.6 \mathrm{~g} / \mathrm{m}^{2}$. day was obtained for the culture grown with nitrate concentration equal to $3.65 \mathrm{mM}$ and a mean rate of photon absorption equal to $17,700 \mu \mathrm{mol}_{h \nu} / \mathrm{kg}_{X_{A}}$.s. TAG productivity and cellular TAG accumulation varied with the nitrate concentration in the feed medium and MRPA. Finally, our results show that TAG productivity can be further increased by optimizing the mean rate of photon absorption through adjusting culture dilution rate and feed-medium nitrate concentration.
\end{abstract}

\section{Introduction}

Microalgal biodiesel and bioethanol are being considered as renewable transportation fuels that can replace or be blended with petroleum fuels. Microalgae can produce large amounts of lipids, such as triacylglycerols (TAGs), that can be converted to biodiesel by transesterification [1]. Alternatively, carbohydrates produced by microalgae can be hydrolyzed and fermented by yeast to produce bioethanol. Microalgae can be cultivated on non-arable land, in brackish or freshwater and they have areal biomass and lipid productivities that are much larger than those of higher plants [2]. Typically, these single-cell microorganisms are cultivated in open ponds or photobioreactors (PBRs) using batch or continuous processes [3]. Batch cultivation is simplest and most common method of cultivating microalgae but it is labor intensive and suffers from downtime associated with harvesting. It also requires the production of seed culture needed to inoculate the PBR [3]. On the other hand, intensified continuous production of biomass or TAGs has the potential to reduce operating and capital costs due to their lower maintenance needs and consistent product quality [4].

Microalgae rich in TAG lipids are produced in nitrogen deprived cultures $[5,6,7,8,9]$. The two most common methods of nitrogen starvation in batch cultures are progressive and sudden starvation. The former requires a small amount of nitrogen to be added initially to the culture medium. The cells grow and consume all the available nitrate in the medium leading to nitrogen starvation. In sudden starvation, biomass is first cultivated in a secondary PBR in nutrient replete conditions. Then, a volume of suspension is harvested and cells separated from the medium, washed to remove all traces of nitrogen, and resuspended in nitrogen-free medium. Both nitrogen starvation processes lead to cell pigment degradation and eventual cell death. The optimization of nitrogen starvation processes is challenging as it is difficult to isolate the effects of each operating condition on TAG productivity due to the simultaneous degradation of pigments, increase in biomass concentration, and continuously changing biochemical composition of the cells.

On the other hand, TAG rich microalgae cells can be produced in 
nitrogen-limited cultures grown in PBRs operated in continuous mode [8]. In chemostat mode the biochemical composition of the cells does not change with time presenting the ideal conditions to examine the effects of various culture conditions on metabolite and biomass productivity. To achieve nitrogen limited growth in chemostat mode a small amount of nitrate is continuously added to the PBR such that the steady-state nitrate concentration in the PBR is very small so as to induce TAG production. Recently, Remmers et al. [10] cultivated wild type and starchless mutant strains of Acutodesmus obliquus in nitrogen limited medium in batch and continuous (turbidostat) modes. The authors exposed a $2 \mathrm{~cm}$ thick airlift PBR containing $1.7 \mathrm{~L}$ of microalgae culture to a photon flux density of $500 \mu \mathrm{mol}_{h \nu} / \mathrm{m}^{2} \cdot \mathrm{s}$ at 16:8 hour light/ dark cycles. The authors reported a maximum cellular TAG concentration of 43 and 33 dry wt $\%$ for the starchless mutant in batch and continuous modes, respectively. The corresponding values for the wild type were 26 and 16 dry wt $\%$, respectively. Similarly, the areal TAG productivity of the starchless mutant cultures were 5.8 and $3.1 \mathrm{~g} /$ $\mathrm{m}^{2}$.day in batch and continuous modes, respectively. They were, respectively, 4.6 and $2.2 \mathrm{~g} / \mathrm{m}^{2}$.day for the wild type. Moreover, the authors reported that wild type A. obliquus cells only began accumulating significant amounts of TAGs when cellular starch concentration reached its maximum concentration of $40 \%$ by dry wright. Del Rio et al. [11] cultivated Chlorococcum oleofaciens and Pseudokirchneriella subcapitata in chemostat mode in a $2 \mathrm{~L}$ PBR exposed to a photon flux density of $3500 \mu \mathrm{mol}_{h \nu} / \mathrm{m}^{2} \cdot \mathrm{s}$ and dilution rate of $0.00831 / \mathrm{h}$. The PBRs were supplied with nitrate at concentrations ranging from 1 to $10 \mathrm{mM}$. The largest fatty acid productivity by $P$. subcapitata was reported to be $2.6 \mathrm{~g} / \mathrm{m}^{2}$.day achieved using a medium with nitrate concentration ranging from 3 to $5 \mathrm{mM}$.

Kandilian et al. [9] demonstrated a correlation between cellular TAG accumulation and productivity and the mean rate of photon absorption (MRPA). The latter is a function of incident irradiance and light attenuation in the PBR depending on biomass concentration and cellular pigment content. Optimization of photon absorption rate of a culture in batch mode is complex due to the temporal evolution of parameters affecting photon absorption rate such as cell size, pigment content, and biomass concentrations. Benvenuti et al. [12] used the ratio of incident irradiance and the initial biomass concentration of the sudden starvation batch culture to optimize batch nitrogen starvation cultures with respect to light. The authors observed that TAG productivity increased linearly with increasing irradiance to initial biomass concentration ratio up to $1 \mathrm{~mol}_{h \nu} / \mathrm{g}$.day. Beyond this value no increase in TAG productivity was observed.

This study aims to elucidate the role of photon absorption rate and nitrate concentration on the TAG accumulation and productivity in nitrogen limited PBRs operated in chemostat mode. It also presents guidelines for optimizing TAG production in continuous nitrogen limited cultures.

\section{Background}

\subsection{Parachlorella kessleri}

Recently, Taleb [13] screened nine freshwater and saltwater microalgae strains, including Nannochloropsis, scenedesmus, Chlorella, and Neochloris species, for their suitability for biodiesel production. The authors demonstrated that the freshwater green microalgae $P$. kessleri was the most productive of all nine strains screened. $P$. kessleri is a green microalgae with a diameter between 3 and $6 \mu \mathrm{m}$ characterized by fast growth rate under optimal and nitrogen limited conditions. Indeed, its productivity during nitrogen starvation can reach up to $4.4 \mathrm{~g} / \mathrm{m}^{2}$.day [14]. It also accumulates large amounts of carbon reserves in nitrogen or phosphate-limited media [15]. In nutrient replete conditions the cells typically contain a small amount of lipids, up to $10 \%$ by dry weight. During nitrogen limitation the cells may accumulate up to $60 \%$ starch or up to $50 \%$ lipids by dry weight depending on nitrogen availability and illumination conditions $[16,15,17,14]$.

\subsection{Light transfer in PBRs}

The kinetics of microalgal growth are typically proportional to the local specific rate of photon absorption (LRPA), $\mathscr{A}$ expressed in $\mu \mathrm{mol}_{h \nu} /$ $\mathrm{kg}_{X}$.s [18]. It represents the amount of photons absorbed in the PAR region defined by the spectral region between 400 and $700 \mathrm{~nm}$, per unit time and per unit weight of biomass. It can be obtained from the volumetric rate of photon absorption $\mathscr{A}_{V}(z)$ which depends on the absorption cross-section of the microalgae, the PAR-averaged fluence rate in the PBR, and biomass concentration $X$ [19]. The mean volumetric rate of photon absorption $\left\langle\mathscr{A}_{V}\right\rangle$ can be obtained by averaging local values $\mathscr{A}_{V}(z)$ over the volume of the PBR [19]. In a flat plate PBR it can expressed as

$\left\langle\mathscr{A}_{V}\right\rangle=\frac{1}{L} \int_{400}^{700} \int_{0}^{L} X \overline{\mathrm{A}}_{a b s, \lambda} G_{\lambda}(z) d z d \lambda$

where $G_{\lambda}(z)$ is the local fluence rate in $\mu \mathrm{mol}_{h \nu} / \mathrm{m}^{2} \cdot \mathrm{s}, \overline{\mathrm{A}}_{a b s, \lambda}$ is the mass absorption cross-section of the microalgae (in $\mathrm{m}^{2} / \mathrm{kg}$ ), and $L$ is the thickness of the PBR (in $\mathrm{m}$ ).

In the case of absorbing and scattering media such as microalgal culture, the local spectral fluence rate $G_{\lambda}(z)$ can be obtained by solving the radiative transfer equation [20]. Several methods of solution exist [21-24], however, the two-flux approximation yields satisfactory results for a one-dimensional flat-plate PBR containing strongly forward scattering microalgae $[23,25]$. In the case of normally incident radiation $q_{\lambda, 0}$, the local fluence rate $G_{\lambda}(z)$ at depth $z$ can be expressed as

$\frac{G_{\lambda}(z)}{q_{\lambda, 0}}=2 \frac{\left[\rho_{\lambda}\left(1+\alpha_{\lambda}\right) e^{-\delta_{\lambda} L}-\left(1-\alpha_{\lambda}\right) e^{-\delta_{\lambda} L}\right] e^{\delta_{\lambda} z}+\left[\left(1+\alpha_{\lambda}\right) e^{\delta_{\lambda} L}-\rho_{\lambda}\left(1-\alpha_{\lambda}\right) e^{\delta_{\lambda} L}\right] e^{-\delta_{\lambda} z}}{\left(1+\alpha_{\lambda}\right)^{2} e^{\delta_{\lambda} L}-\left(1-\alpha_{\lambda}\right)^{2} e^{-\delta_{\lambda} L}-\rho_{\lambda}\left(1-\alpha_{\lambda}^{2}\right) e^{\delta_{\lambda} L}+\rho_{\lambda}\left(1-\alpha_{\lambda}^{2}\right) e^{-\delta_{\lambda} L}}$

where $\rho_{\lambda}$ is the diffuse reflectance of the PBRs back wall while the coefficients $\alpha_{\lambda}$ and $\delta_{\lambda}$ are expressed as [25]

$\alpha_{\lambda}=\sqrt{\frac{\overline{\mathrm{A}}_{a b s, \lambda}}{\overline{\mathrm{A}}_{a b s, \lambda}+2 b_{\lambda} \bar{S}_{s c a, \lambda}}}$ and $\delta_{\lambda}=X \sqrt{\overline{\mathrm{A}}_{a b s, \lambda}\left(\overline{\mathrm{A}}_{a b s, \lambda}+2 b_{\lambda} \bar{S}_{s c a, \lambda}\right)}$

Here, $\bar{S}_{s c a, \lambda}$ (in $\mathrm{m}^{2} / \mathrm{kg}$ ) is the average spectral mass scattering crosssection of the microalgae suspension. The backward scattering ratio $b_{\lambda}$ is defined as the fraction of the radiation scattered backwards. It is approximately constant over the PAR region and is estimated from the suspensions scattering phase function [25]. The PAR-averaged fluence rate $G_{P A R}(z)$ can be expressed as

$G_{P A R}(z)=\int_{400}^{700} G_{\lambda}(z) \mathrm{d} z$.

\section{Materials and methods}

\subsection{Cultivation method}

All experiments were conducted using the microalgae Parachlorella kessleri UTEX2229 from the culture collection of UTEX (Austin, TX., USA). It was cultivated in a modified Bold Basal medium with the following composition (in $\mathrm{mM}$ ) $\mathrm{NaNO}_{3}$ 8.02, $\mathrm{Na}_{2}$ EDTA. $2 \mathrm{H}_{2} \mathrm{O}$ 0.122, $\mathrm{MgSO}_{4} \cdot 7 \mathrm{H}_{2} \mathrm{O} \quad 0.83, \mathrm{~K}_{2} \mathrm{HPO}_{4} \quad 0.78, \mathrm{KH}_{2} \mathrm{PO}_{4} 0.88, \mathrm{CaCl}_{2} \cdot 2 \mathrm{H}_{2} \mathrm{O} 0.155$, $\mathrm{FeSO}_{4} \cdot 7 \mathrm{H}_{2} \mathrm{O} 0.046, \mathrm{ZnSO}_{4} \cot 7 \mathrm{H}_{2} \mathrm{O} 7.72 \times 10^{-4}, \mathrm{CuSO}_{4} 4.95 \times 10^{-4}$, $\mathrm{MnCl}_{2} \cdot 4 \mathrm{H}_{2} \mathrm{O} 9.15 \times 10^{-3}, \mathrm{H}_{3} \mathrm{BO}_{3} 4.63 \times 10^{-2}, \mathrm{Co}\left(\mathrm{NO}_{3}\right)_{2} \cdot 6 \mathrm{H}_{2} \mathrm{O}$ $1.51 \times 10^{-4}, \mathrm{Na}_{2} \mathrm{MoO}_{4} 1.06 \times 10^{-3}$, and $\mathrm{NaHCO}_{3} 0.005$.

All experiments were performed in a $3 \mathrm{~cm}$ thick, $1 \mathrm{~L}$ airlift-type flatpanel PBR. The $\mathrm{pH}$ was measured using a $\mathrm{pH}$ sensor (Mettler Toledo SG 3253) and was set to 8 by the injection of $\mathrm{CO}_{2}$ in the PBR when the measured $\mathrm{pH}$ exceeded the setpoint. The temperature was maintained at approximately $22{ }^{\circ} \mathrm{C}$ by forced air convection at the back of the PBR. Air was injected from the bottom of the PBR at the rate of $100 \mathrm{~mL} / \mathrm{min}$ 
to mix the culture. The PBR was illuminated from the front face with a PAR photon flux density (PFD) equal to $250 \mu \mathrm{mol}_{h \nu} / \mathrm{m}^{2}$.s by a white LED light panel (P4 Cool White, Seoul Semiconductor). The incident PFD was measured on the inside surface of the PBR at twelve different locations using a quantum light sensor (Li-250A, Li-COR, Lincoln, NE). The reported PFD was averaged over the 12 locations and showed a variation of less than $10 \%$.

All continuous cultures were operated in chemostat mode. The culture was considered to be in steady state when biomass, pigment, and TAG concentrations were within $5 \%$ of the previous day's measurement for three consecutive days. Moreover, the reported steadystate concentrations of biomass, cell, pigment, total lipid, TAG, protein, and total carbohydrates were the mean of the values measured for three consecutive days. Once the culture reached steady state, the nitrate concentration in the feed medium was adjusted and the culture was allowed to reach a new steady state. A Stepdos pump (08/RC, KNF, Freiburg, Germany) was used to continuously pump fresh medium in the PBR at a culture dilution rate $D$ of $0.011 / \mathrm{h}$, corresponding to $10 \mathrm{~mL} / \mathrm{h}$. The culture was harvested by overflowing the PBR into a sterile harvest bottle.

\subsection{Biomass and pigment concentrations}

Biomass concentration $X$ was measured gravimetrically by filtering $10-15 \mathrm{~mL}$ of culture through a pre-dried and pre-weighed $0.45 \mu \mathrm{m}$ pore size glass-fiber filters. The filters were dried in an oven set to $105^{\circ} \mathrm{C}$ for at least $24 \mathrm{~h}$ and then re-weighed after being cooled in a desiccator for 15 min. Each biomass concentration $X$ measurement was performed in triplicates and the mean value reported.

Photosynthetic pigments were extracted in pure methanol and the concentrations of chlorophyll $a$, chlorophyll $b$, and carotenoids were determined spectrophotometrically. A volume of $0.25-1.5 \mathrm{~mL}$ of culture was centrifuged at $13,400 \mathrm{rpm}(12,100 \mathrm{~g})$ for $10 \mathrm{~min}$. The medium was discarded and the cells were re-suspended in $1.5 \mathrm{~mL}$ of methanol followed by 30 s of sonication. The samples were placed in a dark oven set to $44{ }^{\circ} \mathrm{C}$ to extract for $30 \mathrm{~min}$ and then centrifuged to remove the cell debris. The optical density of the supernatant was measured at wavelengths 480, 652, 665, and $750 \mathrm{~nm}$ using a UV-vis-NIR spectrophotometer (Jasco V-730 Easton, MD). Chlorophyll $a C_{C h l a}$ and $b C_{C h l_{b}}$ concentrations were estimated according to the correlations [26]

$C_{\text {Chla }}[m g / L]=-8.0962\left(O D_{652}-O D_{750}\right)+16.5169\left(O D_{665}-O D_{750}\right)$ $C_{C h l b}[m g / L]=27.4405\left(O D_{652}-O D_{750}\right)-12.1688\left(O D_{665}-O D_{750}\right)$.

The total carotenoid concentration $C_{c a r}$ was estimated based on [27]

$C_{c a r}[m g / L]=4\left(O D_{480}-O D_{750}\right)$.

All pigment extractions were performed in triplicates and the reported concentrations were the mean.

\subsection{Protein concentration}

The Lowry method was used for determining protein concentration of the samples [28]. First, a volume of culture was centrifuged for $10 \mathrm{~min}$ at $13,400 \mathrm{rpm}(12,100 \mathrm{~g})$, the supernatant was discarded, and the cells were re-suspended in $1 \mathrm{~mL}$ of deionized water. Then, one milliliter of $2 \mathrm{~N} \mathrm{NaOH}$ was added to the suspension and the mixture heated to $95^{\circ} \mathrm{C}$ for $6 \mathrm{~min}$. The mixture was then cooled to room temperature and one milliliter of $1.6 \mathrm{~N}$ of HCL was added to neutralize the $\mathrm{pH}$. bovine serum albumin (BSA) was used as the calibration standard for measuring proteins in the range $0.2-0.4 \mathrm{~g} / \mathrm{L}$. Protein concentration measurements were performed in triplicates and the mean values reported.

\subsection{Total carbohydrate concentration}

Total carbohydrate concentration was determined by the phenolsulphuric acid method developed by Dubois et al. [29]. First, a volume of culture containing $X_{C}$ concentration of carbohydrates was centrifuged for $10 \mathrm{~min}$ at $13,400 \mathrm{rpm}(12,100 \mathrm{~g})$, the supernatant was discarded, and the cells were re-suspended in $1 \mathrm{~mL}$ of deionized water. Then, $0.5 \mathrm{~mL}$ of the suspension was added to $0.5 \mathrm{~mL}$ of $50 \mathrm{~g} / \mathrm{L}$ phenol solution in a $15 \mathrm{~mL}$ polypropylene tube. $2.5 \mathrm{~mL}$ of $97 \% \mathrm{H}_{2} \mathrm{SO}_{4}$ was added rapidly to the polypropylene tube and the mixture incubated for $10 \mathrm{~min}$ at room temperature. The mixture was then vortexed for $10 \mathrm{~s}$, incubated for $10 \mathrm{~min}$ at room temperature, and then placed in a $35^{\circ} \mathrm{C}$ for $30 \mathrm{~min}$. Finally, the absorbance of the mixture was measured at $483 \mathrm{~nm}$ using a spectrophotometer (Jasco V-730 Easton, MD). Glucose was used as the calibration standard. All measurements were performed in triplicates and the mean values reported.

\subsection{Total lipids and TAG concentrations}

Lipid extraction was performed according to the whole cell analytic method reported by Van Vooren et al. [7]. First, $20 \mathrm{~mL}$ of biomass was centrifuged at $3600 \mathrm{~g}$ for $10 \mathrm{~min}$ and washed twice with de-ionized water to eliminate traces of salts present in the culture medium. Then, the cells was lyophilized and stored in a freezer at $-80^{\circ} \mathrm{C}$ until they were ready to be analyzed. Approximately $2-4 \mathrm{mg}$ of the lyophilized biomass sample was then resuspended in chloroform/methanol mixture (2:1 by volume) and sonicated for $30 \mathrm{~s}$ followed by $6 \mathrm{~h}$ of light agitation on a shaker placed in a dark area. The extracts were dried using pure gaseous nitrogen and recovered with $1 \mathrm{~mL}$ of chloroform/methanol mixture (2:1 by volume). Triglyceride lipids were separated from the other lipids by solid phase extraction. Finally, the lipids were transesterified and their concentration was measured by gas chromatography with a flame ionization detector. Both total lipids and TAG measurements were performed in triplicates and the mean values reported.

\subsection{Radiation characteristics}

The radiation characteristics of the microorganisms were measured using the method described by Pilon and Kandilian [30]. The microalgae were centrifuged at $13,400 \mathrm{rpm}$ for $10 \mathrm{~min}$ and washed twice with phosphate buffer saline (PBS) solution and suspended in PBS. The normal-normal transmittance measurements were performed using a UV-vis-NIR spectrophotometer (Agilent Cary 5000, Santa Clara, CA) while normal-hemispherical transmittance measurements were performed using the internal integrating sphere accessory (Agilent Cary DRA-2500, Santa Clara, CA) of the same spectrophotometer. The measurements were performed in $1 \mathrm{~cm}$ path length quartz cuvettes (110-10-40 Hellma Analytics, Müllheim, Germany) between the wavelengths 350 and $750 \mathrm{~nm}$. The suspensions were diluted sufficiently to ensure single scattering prevailed. The spectral absorption and scattering cross-sections of the microalgae were measured for three different biomass concentrations to ensure that they were independent of the biomass concentration of the suspension. Finally, the reported cross-sections corresponded to the mean of the three measurements and the error bars correspond to $95 \%$ confidence intervals.

\subsection{Productivity estimation}

The steady-state TAG productivity $R_{T A G}$ was estimated according to $R_{T A G}=D \cdot X \cdot w_{T A G}$

where $w_{T A G}$ is the cellular TAG fraction.

The PAR averaged fluence rate $G_{P A R}(z)$ in the PBR was estimated according to the two-flux approximation [Eq. (2)] [9,25]. It was used to estimate the mean volumetric rate of photon absorption $\left\langle\mathscr{A}_{V}\right\rangle$ using Eq. 


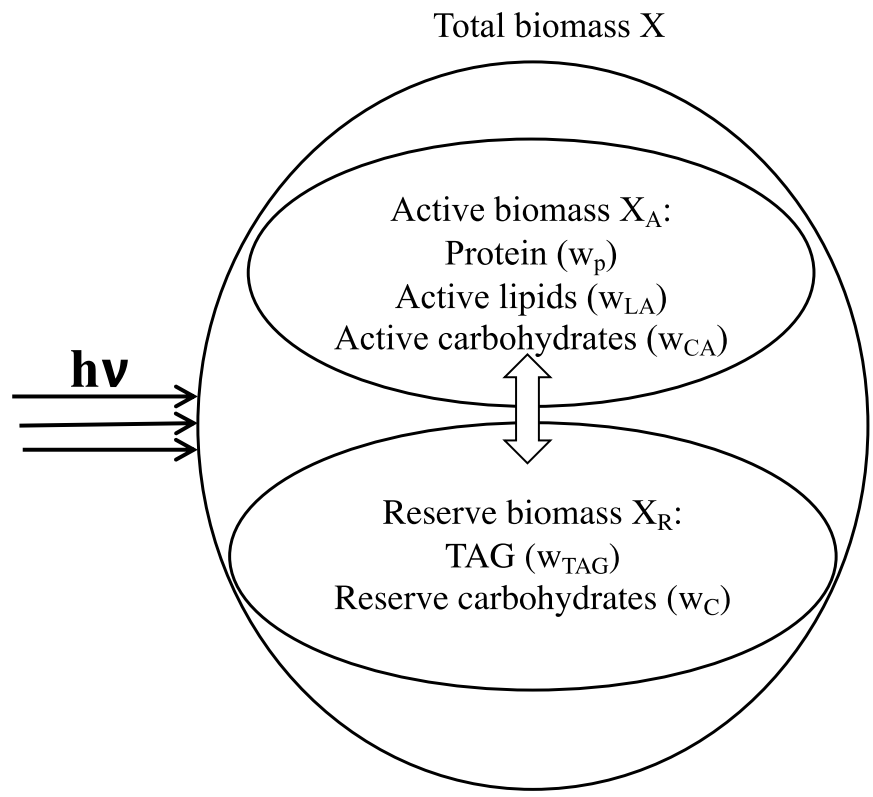

Fig. 1. Representation of the different partitions of biomass in the cell.

(1) which was then expressed per unit biomass to obtain the mean specific rate of photon absorption $\langle\mathscr{A}\rangle$

$\langle\mathscr{A}\rangle=\frac{\left\langle\mathscr{A}_{V}\right\rangle}{X}$.

Fig. 1 illustrates that the total microalgae biomass can be partitioned into active $X_{A}$ and reserve $X_{R}$ biomass such that [31]

$X=X_{A}+X_{R}$.

Active biomass $X_{A}$ is the fraction of biomass that plays a functional role in cell growth and metabolite production while reserve biomass $X_{R}$ is mainly used by cells for carbon storage. Active biomass is composed of proteins and functional carbohydrates and lipids such as those found in cell wall membranes. Reserve biomass $X_{R}$ is composed of intracellular carbohydrates and storage lipids such as TAGs [31]. Reserve biomass $X_{R}$ is typically accumulated in response to environmental stress and serves as carbon storage and is expressed as

$X_{R}=w_{T A G} X+w_{C} X-w_{C A} X_{A}$

where $w_{T A G}$ and $w_{C}$ are mass fractions of TAGs and total carbohydrates, respectively, while $w_{C A}$ is the mass fraction of active carbohydrates in the biomass.

Here, it was assumed that reserve biomass consisted of reserve carbohydrates and TAG lipids. Furthermore, in optimally grown cultures the cells accumulated negligible amounts of reserve carbohydrates. Then, the mass fraction of active carbohydrates $w_{C A}$ could be estimated according to $w_{C A}=X_{C} / X$ where $X_{C}$ is the carbohydrate concentration of cultures grown in light limited conditions, i.e., no nutrient limitation. The fraction of active biomass that was composed of carbohydrates $w_{C A}$ was assumed to be constant for all the nitrogen limited cultures and it was subtracted from the total carbohydrate concentration in the biomass $w_{C} X$. Combining Eqs. (9) and (10), the active biomass $X_{A}$ can be expressed as a function of the total biomass $X$ according to

$X_{A}=\frac{1-w_{T A G}-w_{C}}{1-w_{C A}} X$.

Finally, the absorbed radiant energy is only used by the active portion of the cell biomass to maintain cellular functions and produce metabolites. Therefore, the mean specific rate of photon absorption was expressed per unit active biomass $X_{A}$ such that (a)
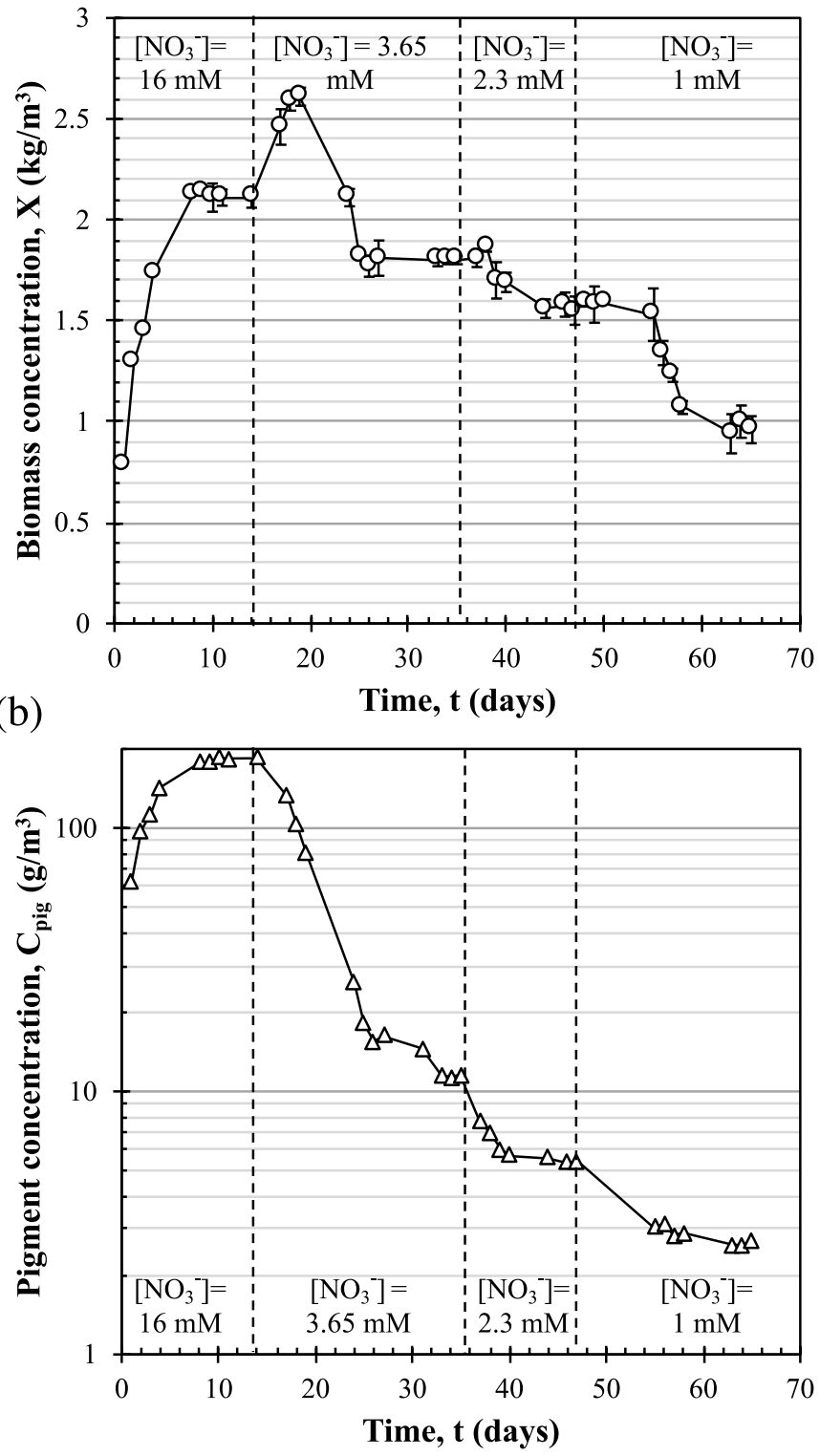

Fig. 2. (a) Biomass and (b) pigment concentrations of Parachlorella kessleri culture grown in chemostat mode with a dilution rate of $0.0111 / \mathrm{h}$, PFD of $250 \mu \mathrm{mol} / \mathrm{m}^{2}$ s and medium nitrogen concentrations of $16,3.65,2.3$, and $1 \mathrm{mM}$. Data shown as mean $\pm \mathrm{SD}, n=3$.

$\left\langle\mathscr{A}_{X A}\right\rangle=\frac{\left\langle\mathscr{A}_{V}\right\rangle}{X_{A}}$

\section{Results}

\subsection{Biomass, pigments, and TAG concentrations}

Panels $\mathrm{a}$ and $\mathrm{b}$ in Fig. 2 respectively show biomass and total pigment concentrations of $P$. kessleri grown in a PBR operated in chemostat mode with a dilution rate of $0.0111 / \mathrm{h}$ and nitrate concentration $\left[\mathrm{NO}_{3}^{-}\right]$ equal to $16,3.65,2.3$, or $1 \mathrm{mM}$. The steady-state biomass $X$ and pigment $C_{p i g}$ concentrations of the culture were $2.11 \mathrm{~kg} / \mathrm{m}^{3}(2.11 \mathrm{~g} / \mathrm{L})$ and $184 \mathrm{~g} / \mathrm{m}^{3}(184 \mathrm{mg} / \mathrm{L})$, respectively, when nitrate was supplied in excess, i.e., $\left[\mathrm{NO}_{3}^{-}\right]=16 \mathrm{mM}$. After reducing the nitrate concentration in the medium from $16 \mathrm{mM}$ to $3.65 \mathrm{mM}$ there was an initial increase in biomass concentration up to $2.6 \mathrm{~kg} / \mathrm{m}^{3}$. This was attributed to a 
Table 1

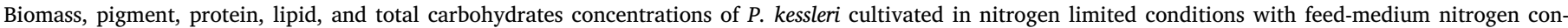

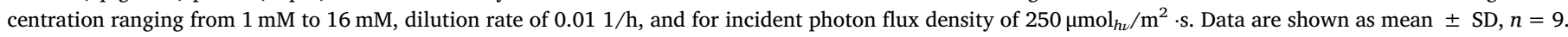

\begin{tabular}{|c|c|c|c|c|c|c|c|c|c|c|c|}
\hline $\begin{array}{l}\text { Nitrate } \\
{\left[\mathrm{NO}_{3}^{-}\right]} \\
(\mathrm{mM})\end{array}$ & $\begin{array}{l}\text { Biomass } \\
X \\
\left(\mathrm{~kg} / \mathrm{m}^{3}\right)\end{array}$ & $\begin{array}{l}\text { Cell } \\
N_{T} \\
\text { (cells/mL) }\end{array}$ & $\begin{array}{l}\text { Pigments } \\
C_{p i g} \\
\left(\mathrm{~g} / \mathrm{m}^{3}\right)\end{array}$ & $\begin{array}{l}\text { Chla } \\
C_{\text {chla }} \\
\text { (dry wt\%) }\end{array}$ & $\begin{array}{l}\text { Chlb } \\
C_{\text {chlb }} \\
\text { (dry wt\%) }\end{array}$ & $\begin{array}{l}\text { Carotnoids } \\
C_{P P C} \\
\text { (dry wt\%) }\end{array}$ & $\begin{array}{l}\text { Total lipid } \\
w_{L} \\
(\text { dry } w \mathrm{t} \%)\end{array}$ & $\begin{array}{l}\text { TAG } \\
w_{T A G} \\
(\text { dry wt } \%)\end{array}$ & $\begin{array}{l}\text { Carbohydrates } \\
w_{C} \\
(\text { dry } w \mathrm{t} \%)\end{array}$ & $\begin{array}{l}\text { Protein } \\
w_{P} \\
(\text { dry } w t \%)\end{array}$ & $\begin{array}{l}\text { Active biomass } \\
X_{A} \\
\left(\mathrm{~kg} / \mathrm{m}^{3}\right)\end{array}$ \\
\hline 16 & $2.11 \pm 0.05$ & $7.8 \times 10^{7}$ & $184 \pm 0.20$ & 5.2 & 1.1 & 1.3 & $11 \pm 1.1$ & $7 \pm 0.99$ & $25 \pm 0.34$ & $58 \pm 2.0$ & 2.05 \\
\hline 5 & $1.9 \pm 0.06$ & - & $58 \pm 0.14$ & 2.0 & 0.49 & 0.61 & $13 \pm 0.24$ & $8.6 \pm 0.90$ & - & - & 1.05 \\
\hline 3.65 & $1.8 \pm 0.04$ & $6.6 \times 10^{7}$ & $11 \pm 0.12$ & 0.39 & 0.084 & 0.15 & $21 \pm 1.4$ & $20 \pm 0.79$ & $64 \pm 3.3$ & $14 \pm 1.4$ & 0.41 \\
\hline 2.3 & $1.6 \pm 0.06$ & $4.8 \times 10^{7}$ & $5.5 \pm 0.11$ & 0.24 & 0.04 & 0.1 & $19 \pm 0.93$ & $16 \pm 0.93$ & $50 \pm 2.3$ & $8.5 \pm 1.3$ & 0.72 \\
\hline 1 & $0.98 \pm 0.08$ & $8.4 \times 10^{6}$ & $2.6 \pm 0.06$ & 0.16 & 0.032 & 0.093 & $27 \pm 0.68$ & $24 \pm 1.1$ & $46 \pm 1.1$ & $9 \pm 2.0$ & 0.39 \\
\hline
\end{tabular}

transient increase in the rate of photon absorption in the PBR due to the penetration of light deeper in the PBR as a consequence of the decrease in pigment concentration of the cells. However, once the culture reached the new steady-state conditions, biomass $X$ and pigment $C_{p i g}$ concentrations were equal to $1.8 \mathrm{~kg} / \mathrm{m}^{3}$ and $11 \mathrm{~g} / \mathrm{m}^{3}$, respectively. As expected, the culture with the smallest nitrate concentration $\left(\left[\mathrm{NO}_{3}^{-}\right]=1 \mathrm{mM}\right)$ featured the smallest biomass and pigment concentrations, respectively, equal to $0.98 \mathrm{~kg} / \mathrm{m}^{3}$ and $2.6 \mathrm{~g} / \mathrm{m}^{3}$. These corresponded to $50 \%$ and $99 \%$ reduction in biomass and pigment concentration compared to the culture grown in nutrient replete medium illustrating that biomass and pigment concentrations decreased in a disproportionate amounts and in an unpredictable way in response to nitrogen limitation. Both biomass and pigment concentrations affect the photon absorption rate in the PBR resulting in vastly different mean rate of photon absorption in cultures grown using difference nitrate concentrations.

Table 1 summarizes biomass, pigment concentrations and the cellular total lipid, TAG, total carbohydrates, and protein fractions for cultures grown with feed-medium nitrate concentration $\left[\mathrm{NO}_{3}^{-}\right]$equal to $16,5,3.65,2.3$, and $1 \mathrm{mM}$. The cellular protein and carbohydrate concentrations were 58 and 25 dry wt $\%$, respectively, when nitrate was supplied in excess. However, the steady-state carbohydrate concentration increased up to 64 dry wt $\%$ when nitrate concentration was reduced to $3.65 \mathrm{mM}$. This illustrated that the cells preferentially accumulated carbohydrates as carbon reserve in response to nitrogen limitation, as previously reported by Li et al. [15], possibly due to light limitation. Moreover, as the nitrate concentration in the feed medium decreased so did carbohydrate concentration in the biomass. In fact, steady-state total carbohydrates concentration of the culture was equal to 50 and $46 \mathrm{dry}$ wt $\%$ when nitrate concentration in the feed medium was 2.3 and $1 \mathrm{mM}$, respectively. Moreover, the steady-state protein concentration in nitrogen limited cultures decreased by $84 \%$ to 9 dry wt $\%$ when nitrate concentration in the medium was reduced from $16 \mathrm{mM}$ to $1 \mathrm{mM}$. This indicated that majority of the biomass present in nitrogen-limited cultures were in the form of carbon reserves, i.e., reserve carbohydrates and TAGs.

Table 1 also shows the active biomass concentration $X_{A}$ estimated using Eq. (11). It illustrates the decline in the active biomass concentration as the nitrogen concentration in the feed-medium decreased. For example, in optimal growth conditions, approximately $90 \%$ of the biomass was active compared to only $21 \%$ for the culture grown with nitrate concentration equal to $3.65 \mathrm{mM}$.

Fig. 3 plots the average cell mass and cell concentration $N_{T}$ in continuous $P$. kessleri cultures grown with feed-medium nitrate concentration $1,2.2,3.65$, or $16 \mathrm{mM}$. The cell concentration $N_{T}$ was larger in cultures grown with larger feed-medium nitrate concentration. The average cell mass estimated as $X / N_{T}$ was equal to $27 \mathrm{pg} /$ cell during optimal growth conditions but increased 4.25 fold to $115 \mathrm{pg} /$ cell for cells grown in nitrogen limited conditions. It illustrates the increase in average cell mass when the culture was nitrogen limited due to the accumulation of biomass reserve in cells.

Fig. 4 plots the cellular TAG fraction $w_{T A G}$ and TAG productivity $R_{T A G}$ as a function of nitrate concentration in the feed medium. The

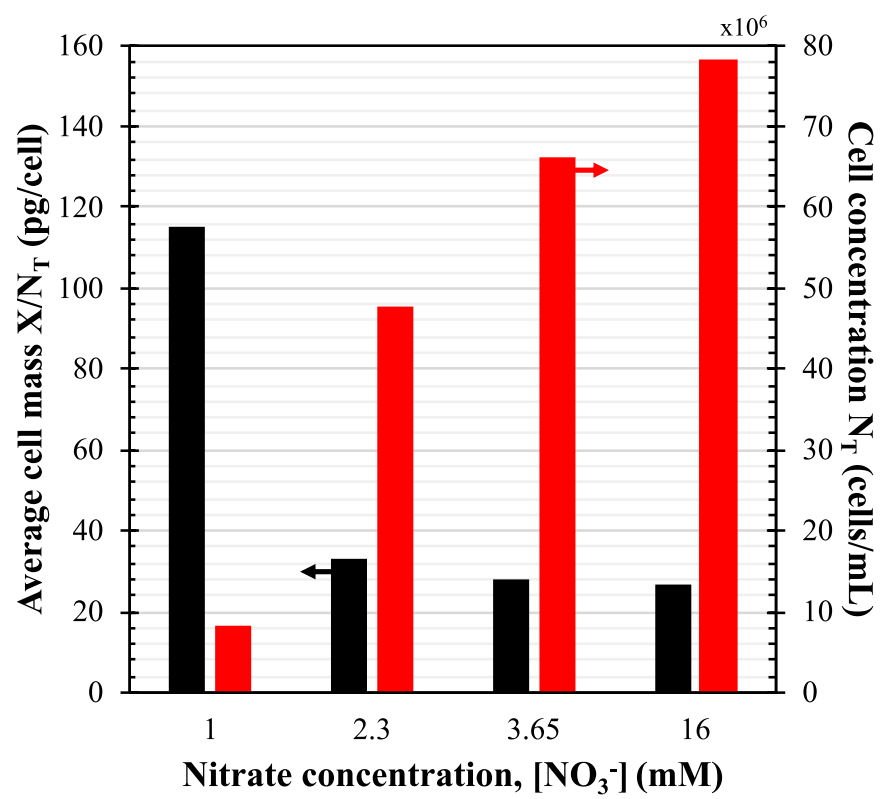

Fig. 3. Average cell mass and cell concentration of $P$. kessleri cultures grown in chemostat mode with feed-medium nitrate concentration $1,2.2,3.65$, or $16 \mathrm{mM}$ and dilution rate of $0.011 / \mathrm{h}$.

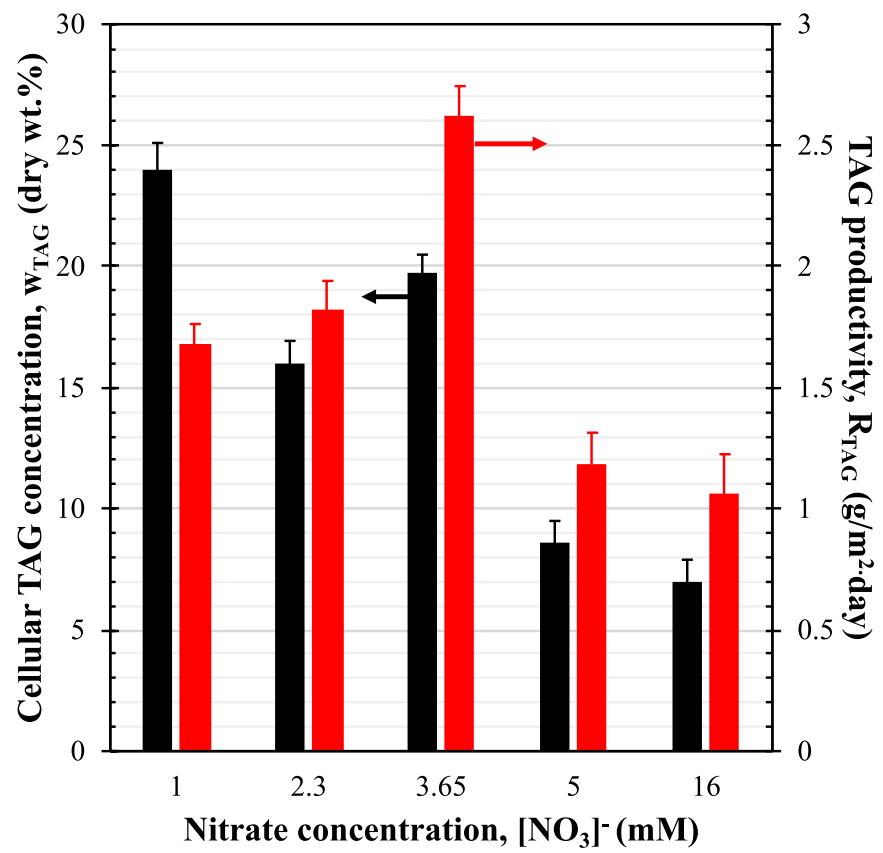

Fig. 4. TAG concentration $w_{T A G}$ and TAG productivity $R_{T A G}$ of $P$. kessleri of continuous cultures with feed medium nitrate concentration of $1,2.3,3.56,5$, and $16 \mathrm{mM}$. Data are shown as means $\pm \mathrm{SD}, n=9$. 
TAG concentration $w_{\text {TAG }}$ was equal to $7 \mathrm{dry} w \mathrm{wt} \%$ and TAG productivity $R_{T A G}$ was $1.1 \mathrm{~g} / \mathrm{m}^{2}$.day when the culture was grown in nutrient replete conditions. Nitrogen limited cultures featured a larger cellular TAG fraction compared to those grown in nutrient replete conditions. The maximum areal TAG productivity $R_{T A G}$, equal to $2.6 \mathrm{~g} / \mathrm{m}^{2}$.day, was obtained when cells were grown with feed-medium containing nitrate concentration $\left[\mathrm{NO}_{3}^{-}\right.$] equal to $3.65 \mathrm{mM}$. The latter did not achieve the largest cellular TAG fraction suggesting that to achieve large TAG productivity the culture must feature both (1) large biomass productivity and (2) large cellular TAG fraction. Indeed, the culture grown with $1 \mathrm{mM}$ of nitrates, i.e., the culture with the smallest concentration of nitrates in the feed-medium featured the largest cellular TAG fraction of 24 dry wt $\%$ but it suffered from the lowest areal biomass productivity $\left(7 \mathrm{~g} / \mathrm{m}^{2}\right.$.day) resulting in TAG productivity $R_{T A G}$ of $1.65 \mathrm{~g} / \mathrm{m}^{2} \cdot$ day. Note that there was no clear relationship between nitrate concentration in the feed medium and cellular TAG fraction or TAG productivity indicating that nitrogen limitation was not the only factor affecting TAG accumulation in cells. This was consistent with previous findings suggesting that nitrogen limitation was necessary but not sufficient for producing cells rich in TAG lipids [5,7,32]. This was illustrated more clearly with the culture fed with nitrate concentration of $5 \mathrm{mM}$. Here, the cells were nitrate limited as evident by the $68 \%$ reduction in pigment concentration in the culture but they did not accumulate large amounts of TAG lipids. Indeed, as previously reported large mean rate of photon absorption was necessary to produce biomass containing large concentration of TAG lipids [32].

\subsection{Radiation characteristics of P. kessleri}

\subsubsection{Scattering phase function}

Fig. 5 shows the measured scattering phase function at $633 \mathrm{~nm}$ of $P$. kessleri suspension grown in nutrient replete conditions. The scattering phase function was assumed to be independent of medium nitrate concentration [33]. As expected, given the large cell diameter compared with the wavelength of light, scattering was mainly in the forward direction with asymmetry factor of $g_{633}=0.989$ at $633 \mathrm{~nm}$. Furthermore, the backward scattering ratio $b_{633}$ was very small and equal to 0.002 . These values are consistent with those reported for other microalgae of similar size and shape [9,33-36].

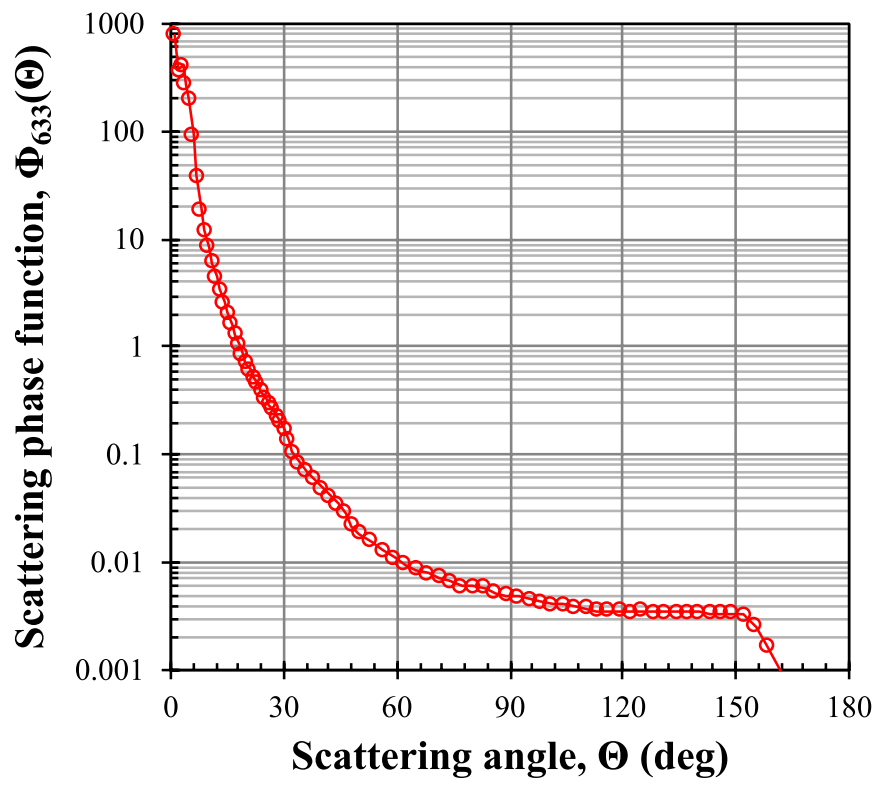

Fig. 5. The scattering phase function of $P$. kessleri culture at $\lambda=633 \mathrm{~nm}$ during nutrient replete growth phase, i.e., culture with nitrate concentration of $16 \mathrm{mM}$. (a)
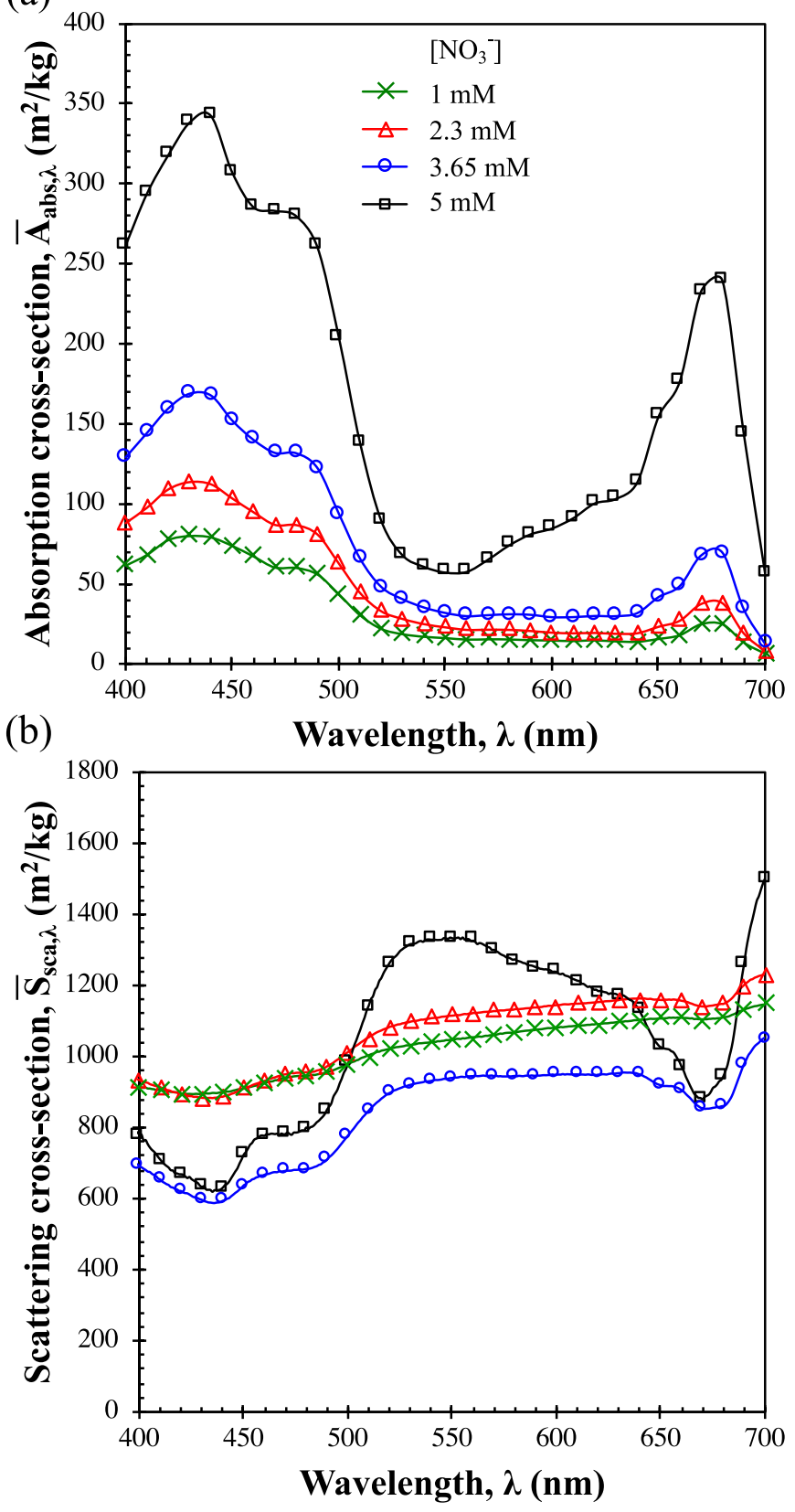

Fig. 6. Absorption $\overline{\mathrm{A}}_{a b s, \lambda}$ and scattering $\bar{S}_{s c a, \lambda}$ cross-sections of $P$. kessleri cultures grown in chemostat mode with medium concentration corresponding to nitrate concentration of $1,2.3,3.65$, or $5 \mathrm{mM}$. Data are shown as mean $\pm \mathrm{SD}, n=3$. Note that error bars were smaller than the symbols.

\subsubsection{Absorption and scattering cross-sections}

Panels a and b in Fig. 6, respectively, show the absorption $\overline{\mathrm{A}}_{a b s, \lambda}$ and scattering $\bar{S}_{s c a, \lambda}$ cross-sections of $P$. kessleri cells grown in chemostat mode with medium nitrate concentration corresponding to $5,3.65,2.3$, $1 \mathrm{mM}$. As previously observed with Nannochloropsis oculata, the absorption cross-section decreased across all wavelengths with decreasing nitrogen concentration in the medium [32,33]. The decrease in absorption cross-section was consistent with the reduction in cellular pigment concentration. The absorption cross-section at $435 \mathrm{~nm} \overline{\mathrm{A}}_{a b s, 435}$ decreased by $75 \%$ when the feed-medium nitrate concentration was reduced from $5 \mathrm{mM}$ to $1 \mathrm{mM}$. Moreover, the magnitude and the shape of the scattering cross-section of $P$. kessleri cultures changed slightly for cultures grown with different nitrate concentrations. For example, the scattering cross-section at $550 \mathrm{~nm}$, corresponding to the wavelength 
(a)

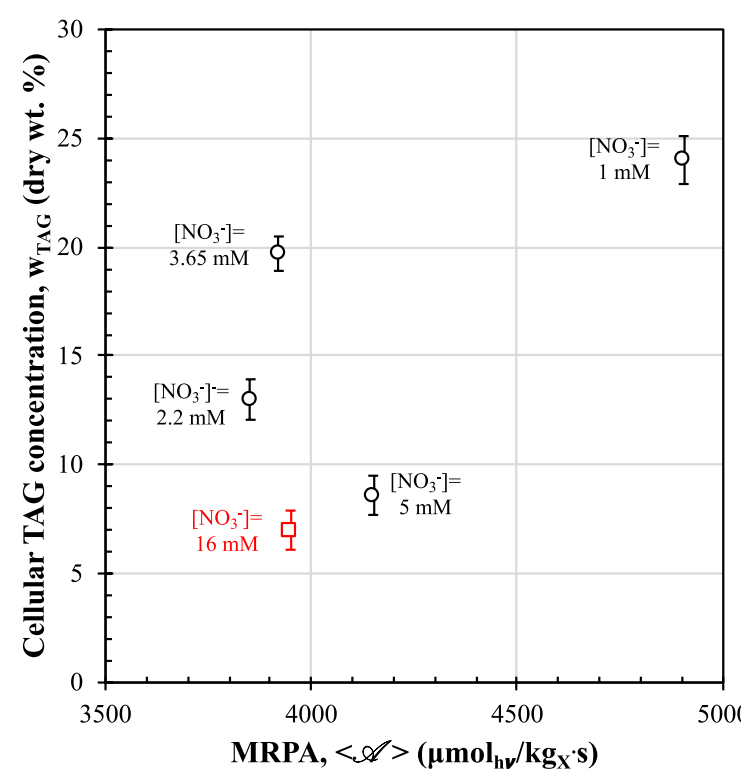

(c)

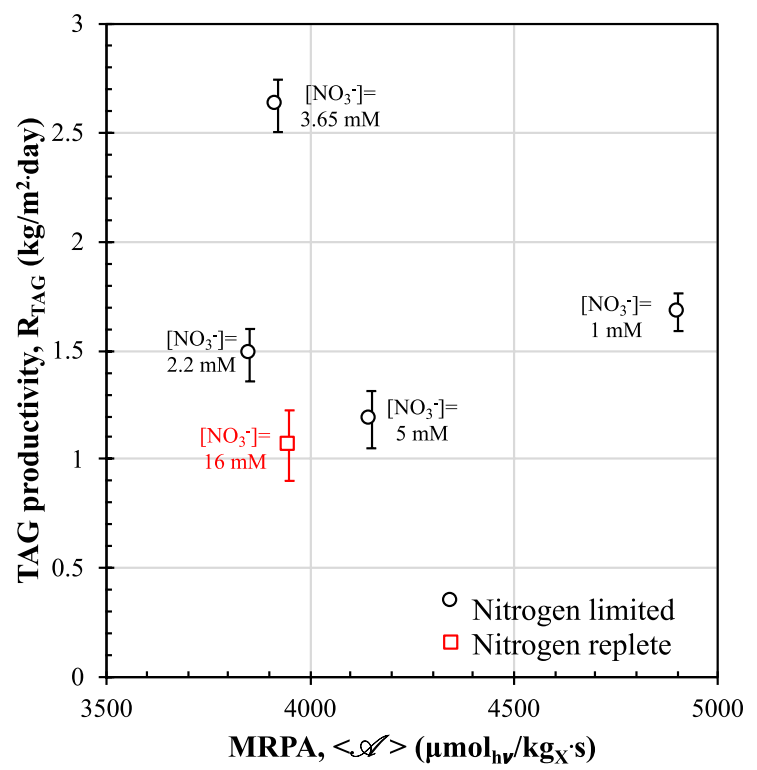

(b)

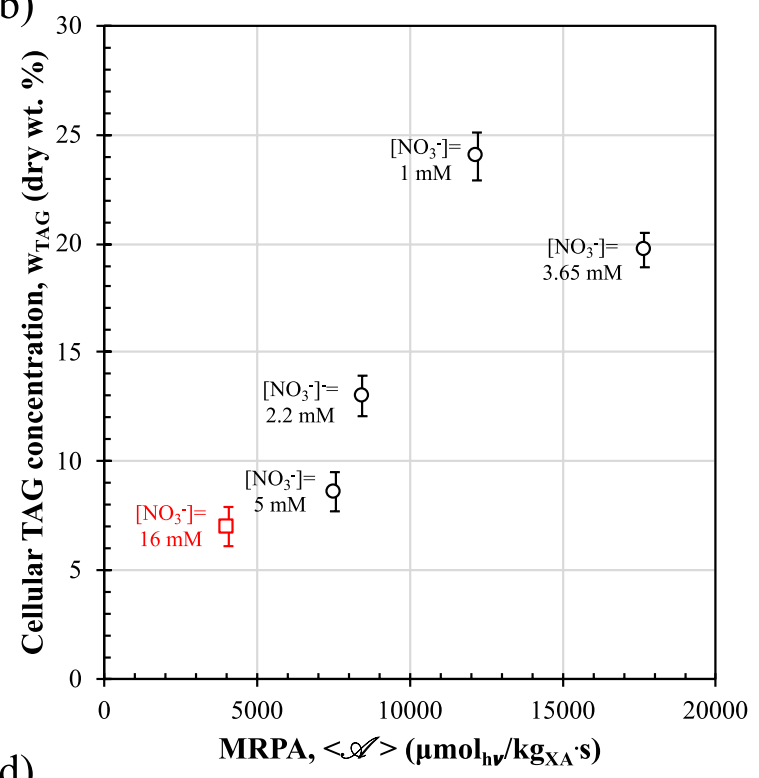

(d)

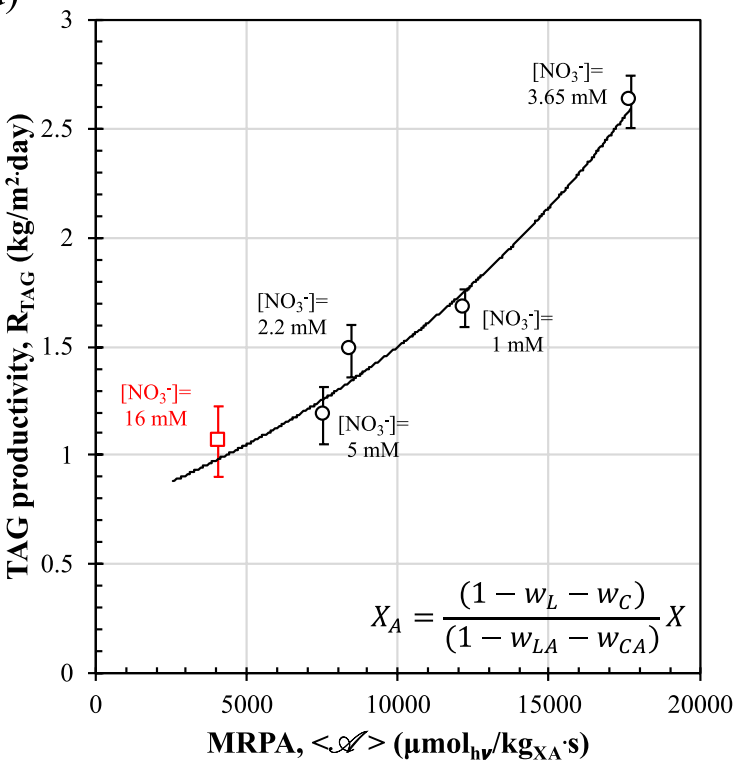

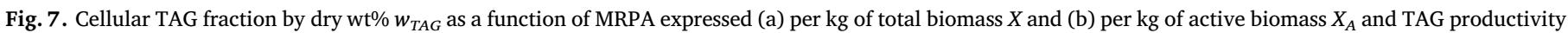
$R_{T A G}$ as a function of MRPA expressed (c) per kg of total biomass $X$ (d) per kg of active biomass $X_{A}$. Data are shown as mean \pm SD, $n=9$.

with lowest absorption cross-section, decreased by $20 \%$ when the nitrate concentration in the medium was adjusted from $16 \mathrm{mM}$ to $1 \mathrm{mM}$. However, it increased by $40 \%$ at $435 \mathrm{~nm}$ corresponding to one of chlorophyll $a$ absorption peaks. The changes in the shape and magnitude of the scattering cross-section may be due to changes in the cellular pigment concentration, cell size and shape, or biochemical composition of the cells [20].

\subsection{Mean specific rate of photon absorption}

Panels a and b in Fig. 7 show cellular TAG fraction in dry wt $\%$ as a function of mean specific rate of photon absorption $\langle\mathscr{A}\rangle$ in the PBR for the $P$. kessleri cultures grown with different feed-medium nitrate concentration expressed per unit biomass $X$ (noted $\langle\mathscr{A}\rangle$ ) and per unit active biomass $X_{A}$ (noted $\left\langle\mathscr{A}_{X A}\right\rangle$ ), respectively. There was no clear relation between cellular TAG fraction $w_{T A G}$ and MRPA $\langle\mathscr{A}\rangle$ when the latter was estimated per $\mathrm{kg}$ of total biomass $X$. However, there was a clear correlation between cellular TAG fraction $w_{T A G}$ and MRPA $\left\langle\mathscr{A}_{X A}\right\rangle$ expressed per $\mathrm{kg}$ of active biomass $X_{A}$. This confirms our previous statement that
MRPA must be expressed per unit active biomass since that is the portion of biomass that utilizes the absorbed radiant energy. This is the first time that expressing radiant energy absorption per unit active biomass is proposed in the context of TAG productivity and its utility validated.

In general, TAG concentration $w_{T A G}$ increased monotonically with increasing MRPA $\left\langle\mathscr{A}_{X A}\right\rangle$. This observation is consistent with previous findings indicating that a large MRPA was necessary for cells to accumulate large amount of TAG lipids by dry mass [32]. This effect was more apparent and more clearly illustrated here as the continuous culture achieved steady state and physical conditions such as $\mathrm{pH}$, nutrient concentration, fluence rate $G_{P A R}(z)$, and LRPA $\mathscr{A}_{X A}(z)$ in the PBR remained constant with time. The observation is also consistent with the hypothesis that de novo TAG synthesis pathway is activated to quench excess electrons generated in the photosynthetic electron transport chain when cells absorb large quantities of photons [37]. It is hypothesized that energy is sunk in TAG synthesis to prevent damage to cells by reactive oxygen species since the synthesis of fatty acids requires significantly more energy in the form of NADPH compared to 
proteins and carbohydrates of similar mass [37]. This may also explain the activation of secondary carotenoid synthesis pathway along with TAG production. Carotenoids such as $\beta$-carotene, lutein, astaxanthin are esterified along with TAG and stored in lipid bodies to protect cells from large irradiance [37]. This can be observed by the increase in the carotenoid to chlorophyll ratio as seen in cultures with smaller feedmedium nitrate concentration (Table 1). Note that the culture grown with feed-medium nitrate concentration of $3.65 \mathrm{mM}$ featured the largest MRPA $\left\langle\mathscr{A}_{X A}\right\rangle$ but did not accumulate the largest cellular TAG fraction by dry mass $w_{T A G}$. As previously discussed, the cells in this culture utilized the absorbed photons to synthesize carbohydrates (65 dry wt\%) as carbon storage rather than TAGs.

Panels c and d in Fig. 7 show TAG productivity $R_{T A G}$ as a function of mean rate of photon absorption in the PBR for the $P$. kessleri cultures with different feed-medium nitrate concentration expressed per unit biomass $X$ and per unit active biomass $X_{A}$, respectively. Here again, there was no clear relation between TAG productivity and MRPA $\langle\mathscr{A}\rangle$ per $\mathrm{kg}$ of total biomass $X$. However, TAG productivity $R_{T A G}$ increased with increasing MRPA $\left\langle\mathscr{A}_{X A}\right\rangle$ when expressed per kg of active biomass $X_{A}$ indicating that TAG production rate was certainly limited by a reaction governed by light absorption. In this study, maximum TAG productivity reached $2.6 \mathrm{~g} / \mathrm{m}^{2}$.day for the culture featuring MRPA equal to $17,700 \mu \mathrm{mol}_{h \nu} / \mathrm{kg}_{X A}$ S. This is similar to maximum TAG productivity of $2.2 \mathrm{~g} / \mathrm{m}^{2}$.day reported by Remmers et al. [10] for the wild type $A$. obliquus grown in continuous mode with a mean rate of photon absorption estimated to be $13,080 \mu \mathrm{mol}_{h \nu} / \mathrm{kg}_{X A} \mathrm{~s}$. The latter was determined assuming a steady-state biomass and TAG concentrations of $2.45 \mathrm{~kg} / \mathrm{m}^{3}$ (with active biomass fraction 0.52 ) and 22.1 dry $\mathrm{wt} \%$, respectively, and full absorption of the $333 \mu \mathrm{mol}_{h v} / \mathrm{m}^{2} \cdot \mathrm{s}$ incident on the PBR. The similarity of both maximum TAG productivity and its corresponding MRPA reported here and in Ref. [10] provides further confidence in the use of MRPA expressed per $\mathrm{kg}$ of active biomass to optimize TAG productivity in nitrogen limited cultures. Kandilian et al. [32] previously demonstrated TAG productivity in nitrogen starved Nannochloropsis oculata and MRPA had a parabolic relation where maximum productivity occurred at $14 \mu \mathrm{mol}_{h v} / \mathrm{m}^{2}$.s. The difference between the shape of the curves here and what we previously reported is due to expressing MRPA per unit volume in Ref. [32] where as here we express MRPA per unit active biomass $X_{A}$. It may also be due to differences between batch and continuous cultures or the use of different species of microalgae. Nevertheless, both studies demonstrated that it may be possible to adjust the nitrate concentration in cultures to modify carbon flux in cell reserves and to optimize the TAG production rate by controlling the MRPA in the PBR, especially when MRPA is expressed per unit of active biomass.

\subsection{Local fluence rate and rate of photon absorption}

Panels a and b in Fig. 8 show the PAR averaged fluence rate $G_{P A R}(z)$ in the PBR and the corresponding specific rate of photon absorption $\mathscr{A}_{X A}(z)$, respectively, for cultures with nitrate concentration equal to 5 , $3.65,2.3$, and $1 \mathrm{mM}$. The fluence rate in the PBR $G_{P A R}(z)$ increased as the feed-medium nitrate concentration decreased. This was due to the decrease in the biomass and pigment concentrations in the cells as previously mentioned. Similarly, the local rate of photon absorption of cells at the back wall of the PBR $\mathscr{A}_{X A}(L)$ was smaller for cultures with larger nitrate concentration in the feed medium. Note that cultures with smaller back wall fluence rate $G_{P A R}(L)$ or rate of photon absorption $\mathscr{A}_{X A}(L)$ featured larger biomass productivity. Moreover, these cultures with strong light attenuation also suffered from relatively small MRPA $\left\langle\mathscr{A}_{X A}\right\rangle$ leading to the production of a culture with a relatively small cellular TAG fraction $w_{T A G}$. Note that when cells are exposed to large local rate of photon absorption $\mathscr{A}_{X A}(z)$, incident light to biomass or TAG conversion may be inhibited due to the dissipation of energy by cells through fluorescence and heat. In this case, the absorbed light can be wasted as heat rather than being directed into TAG synthesis leading
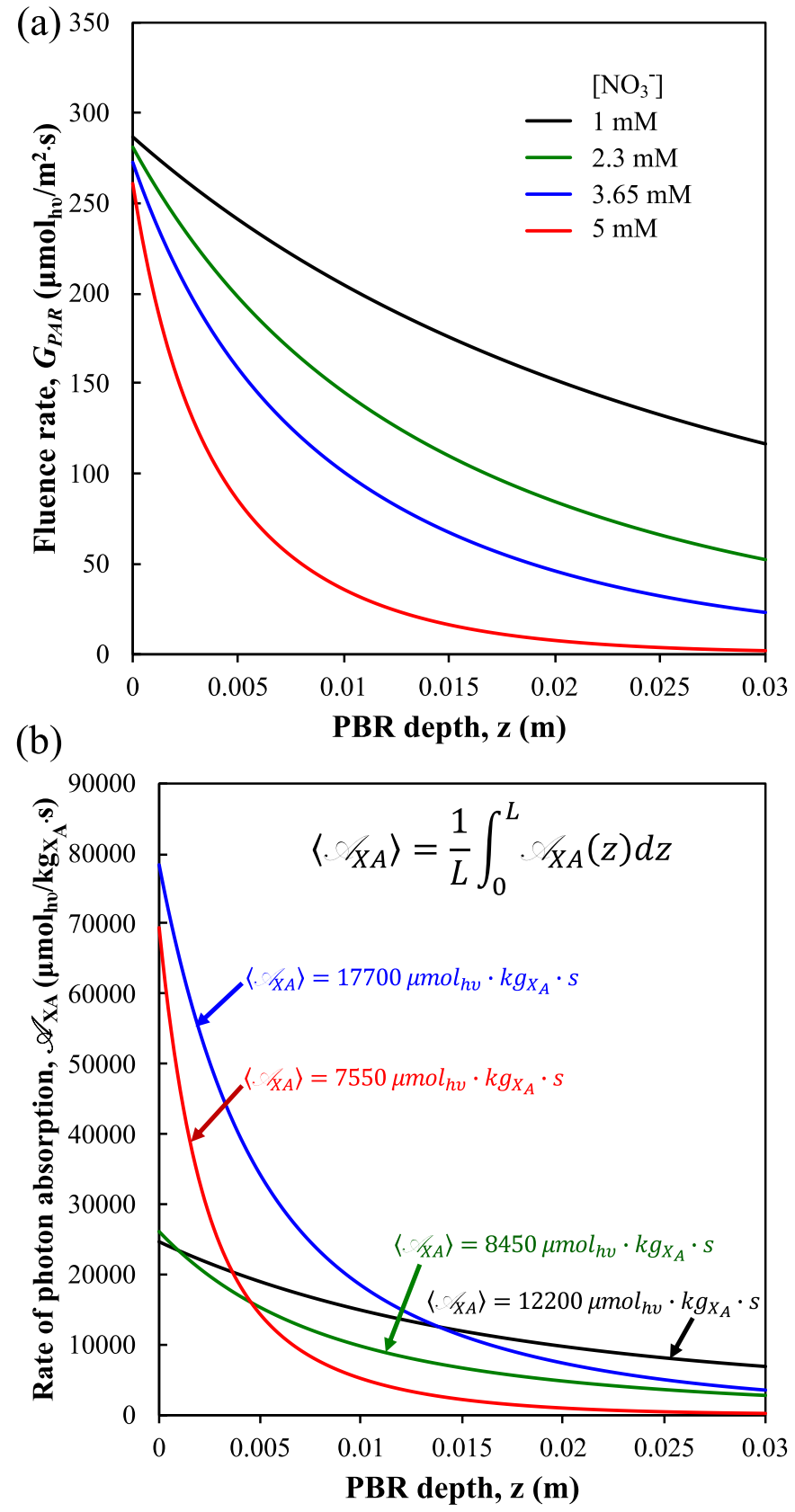

Fig. 8. The PAR averaged fluence rate $G_{P A R}(z)$ and the rate of photon absorption $\mathscr{A}_{X A}(z)$ as a function of PBR depth for nitrogen limited P. kessleri cultures.

to a decrease in TAG productivity. In fact, the cells in the culture with smaller feed-medium nitrogen concentration should be affected more by this phenomenon due to their severely degraded photosystem and their significantly smaller chlorophyll concentration which may explain the decline in biomass productivity of these cultures. During nitrogen starvation, the cells synthesize photoprotective carotenoids and place them in lipid droplets along with TAGs [37]. These photoprotective carotenoids are not part of the photosystem and only absorb the incident radiant energy in order to quench it as heat and protect the photosystem [38]. Therefore, for large MRPA $<\mathscr{A}_{X A}>$ it is expected that some of the absorbed radiant energy will be released as heat and not be used for metabolism.

\section{Discussion}

A maximum TAG productivity of $2.6 \mathrm{~g} / \mathrm{m}^{2}$.day was obtained in this 
study. It was significantly larger than $0.64 \mathrm{~g} / \mathrm{m}^{2}$.day reported for Neochloris oleoabundans grown in turbidostat mode [8]. In turbidostat mode a constant turbiditiy is maintained in the culture as a proxy for cell concentration. However, this does not guarantee a constant photon absorption rate $\mathscr{A}_{X A}(z)$ in the PBR across cultures with different nitrate concentration due to the decrease in cellular pigment concentration in response to reduction in medium nitrogen concentration. The maximum TAG productivity obtained here was also slightly smaller than the maximum TAG productivity of $3.6 \mathrm{~g} / \mathrm{m}^{2}$.day achieved in sudden starvation batch culture of Nannochloropsis oculata with an initial biomass concentration of $0.4 \mathrm{~kg} / \mathrm{m}^{3}$ and an incident irradiance of $250 \mu \mathrm{mol}_{h \nu} /$ $\mathrm{m}^{2}$.s reported by Van Vooren et. al. [7]. Note that the Eustigmatophyte Nannochloropsis oculata and the chlorophyte P. kessleri belong to different classes of microalgae and may have different TAG metabolism and TAG synthesis pathways and therefore they will most likely respond differently to nitrogen limitation.

A maximum cellular TAG fraction of 24 dry wt $\%$ was obtained for the culture feed with nitrate concentration of $1 \mathrm{mM}$. This was significantly smaller than the reported cellular TAG fraction in batch nitrogen starved cultures which can typically reach between 40 and 50 dry wt $\%[5-7,32,39-41]$. The main reason for the low TAG accumulation could be due to the affinity of $P$. kessleri in nitrogen limited cultures to accumulate carbohydrates as the carbon storage medium instead of TAG. A similar trend was observed in batch sudden nitrogen starved $P$. kessleri cultures [13] where cells accumulated up to 60 dry wt $\%$ carbohydrate and 20 dry wt $\%$ TAG at the initiation of nitrogen starvation when the $\mathrm{C} / \mathrm{N}$ of the cells was relatively large. However, as the $\mathrm{C} / \mathrm{N}$ of the cells increased with the progression of nitrogen starvation the cells catabolized the carbohydrates and synthesized TAG lipids leading to a final carbohydrate and TAG concentrations of 30 and 55 dry wt $\%$, respectively [13]. Indeed, Table 1 illustrates that carbohydrate concentration decreased with decreasing nitrate concentration demonstrating that the form of carbon reserves depended on nitrate concentration in the medium. Another reason for the low TAG concentration in the biomass could be explained by the fact that cells did not convert membrane lipids to TAG lipids. TAG production occurs via two methods: de novo synthesis of TAG (acyl CoA-dependent pathway) or by recycling membrane lipids (acyl CoA-independent pathway) [42]. The latter reaction is catalyzed by the enzyme phospholipid:diacylglycerol acyltransferase (PDAT) [37]. In C. reinhardtii and Nannochloropsis oceanica overexpression of the PDAT enzyme has been observed during the early stages of nitrogen starvation $[43,44]$. However, it is likely that in continuous nitrogen limited cultures cells needed to maintain their membrane lipids to sustain cell division and growth and therefore most of the TAG produced in nitrogen limited cultures came from the de novo synthesis pathway. This has the potential to also modify the produced lipid profile and consequently the quality of the produced biodiesel.

Another significant finding was the disproportionate decrease in biomass and pigment concentrations in response to the decrease in medium nitrate concentration. This suggest that there is no linear or obvious relationship between feed-medium nitrate concentration and fluence rate or the rate of photon absorption in the PBR. This complex relationship makes optimization of light absorption in nitrogen limited cultures challenging. Moreover, as much as $420 \%$ increase in the average mass of a cell was observed in nitrogen limited cultures compared to ones grown in optimal conditions. A more thorough investigation must be performed to determine if the radius of the cells increased. Cells grown in optimal conditions are typically composed of $78 \%$ of water by volume [45]. The increase in average cell mass may be due to decrease in cellular water fraction which may be replaced by higher density solid matter. This will significantly affect the optical properties and the radiation characteristics of the microorganisms. The latter is used for performing radiation transfer analysis in nitrogen limited cultures to predict their growth or TAG accumulation kinetics. Such predictions are crucial in optimizing TAG productivity as demonstrated and detailed in the present study.
As previously stated, the two carbon reserve partitions in cells are carbohydrate and TAG lipids. It was demonstrated that cellular carbohydrate and TAG fractions depended on the feed-medium nitrate concentration and the mean rate of photon absorption. Note that, different types of reserve biomass require different amount of energy to synthesize. For example, TAG lipid synthesis may necessitate twice the energy required to produce identical amount of carbohydrates [37]. Therefore, it is inaccurate to simply correlate the mean rate of photon absorbed (MRPA) to the total reserve biomass productivity. The relationship between MRPA and reserve biomass productivity could be refined by introducing a more detailed model that predicts TAG and carbohydrate partitioning during nitrogen limitation.

Several parameters such as the feed-medium nitrate concentration, incident irradiance, or the dilution rate of the culture can be optimized to increase TAG productivity in nitrogen limited chemostat cultures. Such endeavor may be facilitated by first developing a kinetic model that predicts biomass, pigment, and TAG concentrations during nitrogen limitation. Additionally, stable nitrogen limited continuous cultures have not been demonstrated in diurnal light conditions in outdoor PBRs and due to the non-steady illumination condition it may not be trivial to produce microalgae in continuous mode under solar conditions. Finally, the chemostat system presented in this study can be used for transcriptional expression study where the steady-state conditions may enable better understanding of TAG metabolism and TAG synthesis pathways in microalgae.

\section{Conclusions}

This study demonstrated that cellular TAG and carbohydrate productivity in chemostatic $P$. kessleri cultures depended on mean specific rate of photon absorption in the PBR and nitrate concentration in the feed medium with strong interaction between the two due to the decrease in biomass and pigment concentrations. It also demonstrated that mean rate of photon absorption MRPA must be expressed per unit active biomass instead of per unit total biomass. Partitioning of carbon reserves depended on feed-medium nitrate concentration and the mean rate of photon absorption. For nitrate concentration $\left[\mathrm{NO}_{3}^{-}\right] \geq 3.65 \mathrm{mM}$, $P$. kessleri cells preferred to store carbon in the form of carbohydrates whereas cells preferred TAGs as carbon storage medium for $\left[\mathrm{NO}_{3}^{-}\right]<3.65 \mathrm{mM}$. Consequently, TAG accumulation in cells and TAG productivity of the culture were influenced in a complex manner by both the MRPA and nitrate concentration. Finally, photon absorption rate in the PBR and nitrate concentration in the medium must be carefully controlled to maximize TAG productivity.

\section{Conflict of interest statement}

The authors declare no conflict of interest.

\section{Funding}

This project was supported by the French National Research Agency (ANR) project DIESALG (ANR-12-BIME-0001-02).

\section{Declaration of authors' contribution}

JP, RK, and AT are responsible for conception and design of this study. RK, AT, and $\mathrm{VH}$ are responsible for data acquisition and data analysis. RK drafted the article and all authors participated in the interpretation of data and critical revision of the article. RK and JP gave the final approval of the manuscript for submission and are responsible for the integrity of the manuscript as a whole. 


\section{Declarations of interest}

None.

\section{Statement of informed consent, human/animal rights}

No conflicts, informed consent, human or animal rights applicable.

\section{References}

[1] J.W. Moody, C.M. McGinty, J.C. Quinn, Global evaluation of biofuel potential from microalgae, Proc. Natl. Acad. Sci. 111 (23) (2014) 8691-8696.

[2] Y. Chisti, Constraints to commercialization of algal fuels, J. Biotechnol. 167 (3) (2013) 201-214

[3] B.D. Fernandes, A. Mota, J.A. Teixeira, A.A. Vicente, Continuous cultivation of photosynthetic microorganisms: approaches, applications and future trends, Biotechnol. Adv. 33 (6) (2015) 1228-1245.

[4] M.S. Croughan, K.B. Konstantinov, C. Cooney, The future of industrial bioproces sing: batch or continuous? Biotechnol. Bioeng. 112 (4) (2015) 648-651.

[5] J. Pruvost, G. Van Vooren, G. Cogne, J. Legrand, Investigation of biomass and lipids production with Neochloris oleoabundans in photobioreactor, Bioresour. Technol. 100 (23) (2009) 5988-5995.

[6] G. Breuer, P.P. Lamers, D.E. Martens, R.B. Draaisma, R.H. Wijffels, The impact of nitrogen starvation on the dynamics of triacylglycerol accumulation in nine microalgae strains, Bioresour. Technol. 124 (2012) 217-226.

[7] G. Van Vooren, F. Le Grand, J. Legrand, S. Cuine, G. Peltier, J. Pruvost, Investigation of fatty acids accumulation in Nannochloropsis oculata for biodiesel application, Bioresour. Technol. 124 (2012) 421-432.

[8] A.J. Klok, D.E. Martens, R.H. Wijffels, P.P. Lamers, Simultaneous growth and neutral lipid accumulation in microalgae, Bioresour. Technol. 134 (2013) 233-243.

[9] R. Kandilian, J. Pruvost, J. Legrand, L. Pilon, Influence of light absorption rate by Nannochloropsis oculata on triglyceride production during nitrogen starvation, Bioresour. Technol. 163 (2014) 308-319.

[10] I.M. Remmers, A. Hidalgo-Ulloa, B.P. Brandt, W.A.C. Evers, R.H. Wijffels, P.P. Lamers, Continuous versus batch production of lipids in the microalgae Acutodesmus obliquus, Bioresour. Technol. 244 (2017) 1384-1392.

[11] E. Del Rio, E. Garcia-Gomez, J. Moreno, M.G. Guerrero, M. Garcia-Gonzalez, Microalgae for oil. Assessment of fatty acid productivity in continuous culture by two high-yield strains, Chlorococcum oleofaciens and Pseudokirchneriella subcapitata, Algal Res. 23 (2017) 37-42.

[12] G. Benvenuti, R. Bosma, A.J. Klok, F. Ji, P.P. Lamers, M.J. Barbosa, R.H. Wijffels, Microalgal triacylglycerides production in outdoor batch-operated tubular PBRs, Biotechnol. Biofuels 8 (1) (Jul 2015) 100.

[13] A. Taleb, Production de Biodiesel à Partir des Microalgues: Recherche de Souches Accumulatrices de Lipides et Optimisation des Conditions de Culture en Photobioréacteurs, PhD thesis Université de Nantes, Nantes, France, 2015 (In French)..

[14] A. Taleb, J. Legrand, H. Takache, S. Taha, J. Pruvost, Investigation of lipid production by nitrogen-starved Parachlorella kessleri under continuous illumination and day/night cycles for biodiesel application, J. Appl. Phycol. 30 (2) (2018) 761-772.

[15] X. Li, P. Pribyl, K. Bisova, S. Kawano, V. Cepak, V. Zachleder, M. Cizkova, I. Branyikova, M. Vitova, The microalga Parachlorella kessleri a novel highly efficient lipid producer, Biotechnol. Bioeng. 110 (1) (2013) 97-107.

[16] Y. Mizuno, A. Sato, K. Watanabe, A. Hirata, T. Takeshita, S. Ota, N. Sato, V. Zachleder, M. Tsuzuki, S. Kawano, Sequential accumulation of starch and lipid induced by sulfur deficiency in Chlorella and Parachlorella species, Bioresour. Technol. 129 (2013) 150-155.

[17] T. Takeshita, S. Ota, T. Yamazaki, A. Hirata, V. Zachleder, S. Kawano, Starch and lipid accumulation in eight strains of six Chlorella species under comparatively high light intensity and aeration culture conditions, Bioresour. Technol. 158 (2014) $127-134$.

[18] J.F. Cornet, C.G. Dussap, A simple and reliable formula for assessment of maximum volumetric productivities in photobioreactors, Biotechnol. Prog. 25 (2009) 424-435.

[19] J. Pruvost, J.F. Cornet, Knowledge models for the engineering and optimization of photobioreactors, in: C. Posten, C. Walter (Eds.), Microalgal Biotechnology: Potential and Production, De Gruyter, Berlin, Germany, 2012, pp. 181-224.

[20] M. Jonasz, G.R. Fournier, Light Scattering by Particles in Water: Theoretical and Experimental Foundations, Academic Press, San Diego, CA, 2007.

[21] L. Pilon, H. Berberoğlu, R. Kandilian, Radiation transfer in photobiological carbon dioxide fixation and fuel production by microalgae, J. Quant. Spectrosc. Radiat. Transf. 112 (2011) 2639-2660.
[22] J. Dauchet, S. Blanco, J.-F. Cornet, M. El Hafi, V. Eymet, R. Fournier, The practice of recent radiative transfer Monte Carlo advances and its contribution to the field of microorganisms cultivation in photobioreactors, J. Quant. Spectrosc. Radiat. Transf. (2012) pp. Ü.

[23] E. Lee, R.-L. Heng, L. Pilon, Spectral optical properties of selected photosynthetic microalgae producing biofuels, J. Quant. Spectrosc. Radiat. Transf. 114 (2013) $122-135$.

[24] R. Kandilian, B. Jesus, J. Legrand, L. Pilon, J. Pruvost, Light transfer in agar immobilized microalgae cell cultures, J. Quant. Spectrosc. Radiat. Transf. 198 (2017) $81-92$.

[25] L. Pottier, J. Pruvost, J. Deremetz, J.-F. Cornet, J. Legrand, C.G. Dussap, A fully predictive model for one-dimensional light attenuation by Chlamydomonas reinhardtii in a torous photobioreactor, Biotechnol. Bioeng. 91 (2005) 569-582.

[26] R. Ritchie, Consistent sets of spectrophotometric chlorophyll equations for acetone, methanol and ethanol solvents, Photosynth. Res. 89 (2006) 27-41.

[27] J.D. Strickland, T.R. Parsons, A Practical Handbook of Seawater Analysis, Fisheries Research Board of Canada, Ottawa, Canada, 1968.

[28] O.H. Lowry, N.J. Rosebrough, A.L. Farr, R.J. Randall, Protein measurement with the Folin phenol reagent, J. Biol. Chem. 193 (1) (1951) 256-275.

[29] M. Dubois, K.A. Gilles, J.K. Hamilton, P.A. Rebers, F. Smith, Colorimetric method for determination of sugars and related substances, Anal. Chem. 28 (3) (1956) 350-356.

[30] L. Pilon, R. Kandilian, Interaction between light and photosynthetic microorganisms, in: J. Legrand (Ed.), Thematic Issue on Photobioreaction Engineering, Advances in Chemical Engineering, vol. 46, Elsevier, The Netherlands, 2015.

[31] Cornet. J.-F, C.G. Dussap, J.-B. Gros, Kinetics and energetics of photosynthetic micro-organisms in photobioreactors, Bioprocess and Algae Reactor Technology, Apoptosis, Advances in Biochemical Engineering Biotechnology, vol. 59, Springer, Berlin Heidelberg, 1998, pp. 153-224.

[32] R. Kandilian, T.-C. Tsao, L. Pilon, Control of incident irradiance on a batch operated flat-plate photobioreactor, Chem. Eng. Sci. 119 (2014) 99-108.

[33] R. Kandilian, E. Lee, L. Pilon, Radiation and optical properties of Nannochloropsis oculata grown under different irradiances and spectra, Bioresour. Technol. 137 (2013) 63-73.

[34] R. Kandilian, R.-L. Heng, L. Pilon, Absorption and scattering by fractal aggregates and by their equivalent coated spheres, J. Quant. Spectrosc. Radiat. Transf. 151 (2015) 310-326.

[35] R. Kandilian, J. Pruvost, A. Artu, C. Lemasson, J. Legrand, L. Pilon, Comparison of experimentally and theoretically determined radiation characteristics of photosynthetic microorganisms, J. Quant. Spectrosc. Radiat. Transf. 175 (2016) 30-45.

[36] R. Kandilian, A. Soulies, J. Pruvost, B. Rousseau, J. Legrand, L. Pilon, Simple method for measuring the spectral absorption cross-section of microalgae, Chem. Eng. Sci. 146 (2016) 357-368.

[37] O. Hu, M. Sommerfeld, E. Jarvis, M. Ghirardi, M. Posewitz, M. Seibert, A. Darzins, Microbial triacylglycerols as feedstocks for biofuel production: perspectives and advances, Plant J. 54 (2008) 621-639.

[38] Z. Dubinsky, N. Stambler, Photoacclimation processes in phytoplankton: mechanisms, consequences, and applications, Aquat. Microb. Ecol. 56 (2000) 163-176.

[39] J. Pruvost, G. Van Vooren, B. Le Gouic, A. Couzinet-Mossion, J. Legrand, Systematic investigation of biomass and lipid productivity by microalgae in photobioreactors for biodiesel application, Bioresour. Technol. 102 (2011) 150-158.

[40] A. Taleb, R. Kandilian, R. Touchard, V. Montalescot, T. Rinaldi, S. Taha, H. Takache, L. Marchal, J. Legrand, J. Pruvost, Screening of freshwater and seawater microalgae strains in fully controlled photobioreactors for biodiesel production, Bioresour. Technol. 218 (2016) 480-490.

[41] A. Taleb, J. Pruvost, J. Legrand, H. Marec, B. Le-Gouic, B. Mirabella, B. Legeret, S. Bouvet, G. Peltier, Y. Li-Beisson, S. Taha, H. Takache, Development and valida tion of a screening procedure of microalgae for biodiesel production: application to the genus of marine microalgae Nannochloropsis, Bioresour. Technol. 177 (2015) $224-232$

[42] S.-C. Fang, Biofuels from Algae chapter, Metabolic Engineering and Molecular Biotechnology of Microalgae for Fuel Production, first edition, Elsevier, San Diego, CA, 2013, pp. 47-65.

[43] K. Yoon, D. Han, Y. Li, M. Sommerfeld, Q. Hu, Phospholipid:diacylglycerol acyltransferase is a multifunctional enzyme involved in membrane lipid turnover and degradation while synthesizing triacylglycerol in the unicellular green microalga Chlamydomonas reinhardtii, Plant Cell 24 (9) (2012) 3708-3724.

[44] J. Jia, D. Han, H.G. Gerken, Y. Li, M. Sommerfeld, Q. Hu, J. Xu, Molecular mechanisms for photosynthetic carbon partitioning into storage neutral lipids in Nannochloropsis oceanica under nitrogen-depletion conditions, Algal Res. 7 (2015) 66-77.

[45] J. Dauchet, S. Blanco, J.-F. Cornet, R. Fournier, Calculation of the radiative properties of photosynthetic microorganisms, J. Quant. Spectrosc. Radiat. Transf. 161 (2015) 60-84. 